\title{
Mini-Hydro Turbine: Solution to Power Challenges in an Emerging Society with Abundance of Water
}

\author{
Emmanuel Ighodalo Okhueleigbe ${ }^{*}$, Ofualagba Godswill \\ Department of Electrical / Electronic Engineering, Federal University of Petroleum Resources, Effurun, Nigeria \\ Email address: \\ okhueleigbe.emmanuel@fupre.edu.ng (E. I. Okhueleigbe), swillas_solar@yahoo.com (O. Godswill) \\ *Corresponding author
}

\section{To cite this article:}

Emmanuel Ighodalo Okhueleigbe, Ofualagba Godswill. Mini-Hydro Turbine: Solution to Power Challenges in an Emerging Society with Abundance of Water. American Journal of Engineering and Technology Management. Vol. 2, No. 2, 2017, pp. 7-12.

doi: 10.11648/j.ajetm.20170202.11

Received: April 24, 2017; Accepted: April 28, 2017; Published: June 29, 2017

\begin{abstract}
The mini hydro turbine research is aimed at designing and constructing a hydro-electric power plant model that can generate electric power, which can be used at the domestic level to power electrical appliances. There are three main sections for the hydro turbine, such as the pelton wheel which rotate due to falling water from the water storage tank through the penstock, the alternator, been made of a permanent magnet rotor and conducting coil windings on the stator connected to the turbine through a runner, and the feedback system for the continuous flow of water. The result shows that the construction of mini hydro turbine plant is feasible and there were no major problems apparent at the design and implementation stages of the mini hydro turbine power plant.
\end{abstract}

Keywords: Head, Pelton Turbine, Efficiency, Reliability, Alternator

\section{Introduction}

Hydropower generation refers to shaft power from falling water which can be used for direct mechanical purposes or, more frequently, for generating electricity. Hydropower is the most established renewable resource for electricity generation. Although, hydroelectric generation is regarded as a mature technology, there are still possibilities for improvement. [1]

Taking into consideration the power reliability, efficiency, as well as the economic benefits of this technology, the generation of electricity derived from hydro turbine a growing capacity of world-wide installations put at $5 \%$ per year, doubling about every 15 years. More specifically, hydro installations and plants are long lasting (due to continuous steady-state operation without high temperatures and less mechanical stresses), thus producing electricity at low cost with consequent economic benefits. [1-2]

The design of reliable and cost effective small hydropower plants capable of small-scale electrical energy production is a prerequisite for the effective use of hydropower as an alternative resource. In this research, the design of a small hydroelectric plant, will maximize the energy output together with the life-time of the machines. In all cases, the design objective is related to the total output of the overall hydro turbine operation in power terms. [3-4]

Small-scale hydro-electric power plants, with capacities between 1 kilowatt and 1 megawatt, are being developed in some countries. In many Asian countries, as well as other developing nations, research in such area are already developing, which can lead to making good use of locallymade materials and indigenous technology. [5]

Hydro power generation and national grid efficiency could be improved by incorporating domestic-scale hydro generators at the consumer level.

\section{Method}

\subsection{Design Overview}

Turbine is a rotary engine that converts the energy of a moving stream of water, steam or gas into mechanical energy. The basic element in a turbine is a wheel or rotor with paddles, blades or buckets arranged on its circumference in such a way that the moving fluid exerts a tangential force that turns the wheel and imparts energy to it. (source: Wikipedia) 
This mechanical energy is then transferred through a drive shaft to operate a machine, compressor, electric generator or propeller.

In a pelton Turbine, water impitches on the blades of the turbine making the wheel to rotate (due to force of the falling water) producing torque and power through the runner to rotate the alternator/generation at a particular speed thereby producing an electric voltage at the output.

\subsection{Design Analysis}

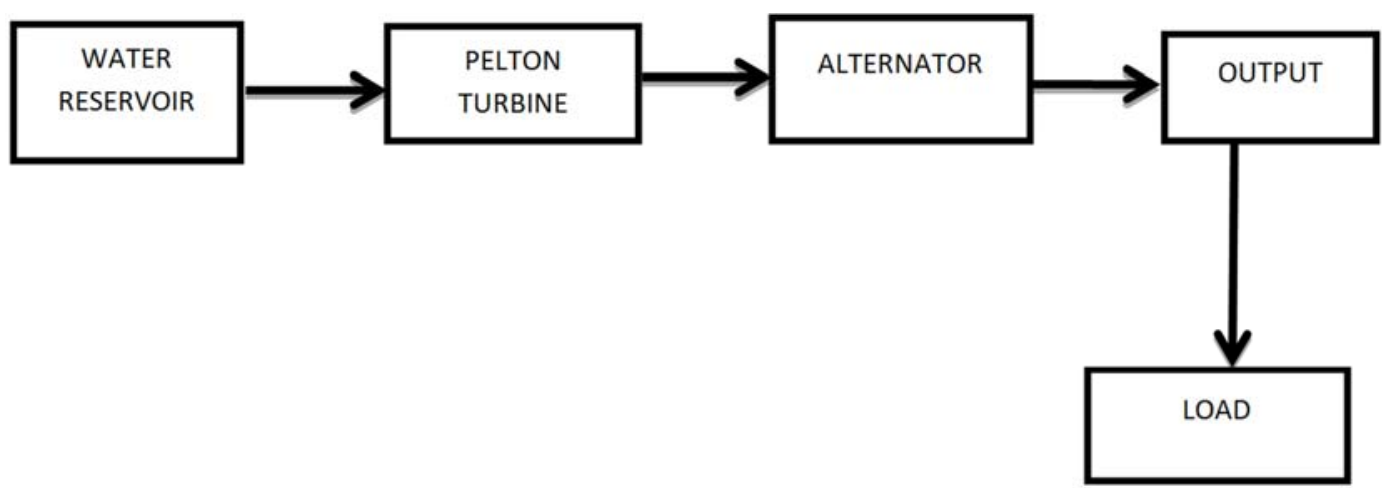

Figure 1. Block diagram of Turbine flow process

\subsection{Water Storage Tank}

The water storage tank can be described as a place where water is stored. The water in the storage tank is usually located on a higher level as compared to the rest of the construction structure. The height of water level in the tank decides how much potential energy the water possesses and the higher the water level, the more tendency its potential energy. [6]

The outflow from the tank was estimated by calculation using the formula

$$
V=\sqrt{2 G H} \text { (kinetic energy and potential energy) }
$$

Where: $\mathrm{V}=$ velocity of flow

$$
\mathrm{G}=\text { the acceleration due to gravity }
$$$$
\mathrm{H}=\text { head }
$$

The size of the water storage tank used is 200liters

\subsection{Penstock Design}

The penstock is a long pipe that conveys the water flowing from the water storage tank to the power generation unit (which is made up of turbines, generators and control/monitoring devices). The water in the penstock possesses kinetic energy due to its motion and potential energy as a result of its height. [7]

The penstock will be made of PVC pipe, PVC elbow joints, valves and nozzle, connecting the water storage tank to the turbine wheel.

\subsection{Turbine}

Water flowing from the penstock is allowed to enter the turbine-part of the power generation unit. When water falls on the blades of the turbine, the kinetic and potential energy of water is converted into a rotational motion on the blades of the turbine. The rotating blades cause the shaft of the turbine (which has been coupled to the generator) to also rotate. [8]

\subsection{Choice of Turbine}

There are various types of water turbines such as Kaplan Wheel turbine, Francis Wheel turbine, Pelton wheels, etc. The type of turbine to be used in the design of hydro-turbine power plant is dependent on the water height, water quantity and the total expected power generation capacity. The PeltonWheel turbine was chosen as a result of the above mentioned reasons and its easy fabrication/construction at the domestic level, and it will be made of locally-sourced materials including metal-cutting disc, 45 degrees PVC elbow joints, bolts, nuts, washers, bearings, etc.

\subsection{Pelton Turbine Design}

The turbine wheel is fabricated locally with 9-inches metal cutting disk with $45^{\circ}$ pvc elbow joint pipe screwed to the metal disk with a spacing of $36^{\circ}$ from each other.

i. Number of blades: The selection of optimum number of blades is very important in the design of Turbine Runner, fewer numbers of blades would result in underutilization of water available to the turbine and excessive number of blades may cause the pulsating power and reducing the turbine efficiency. [9]

$$
\text { Number of blades }=10
$$

ii. Blade spacing: Proper blade spacing allows the water to strike, on the blades for maximum thrust production, the blade spacing depends upon the number of blades used in the turbine runner.[9]

$$
\begin{aligned}
\text { Blade spacing } & =\frac{360}{\text { number of blades }} \\
& =\frac{360}{10}=36^{\circ}
\end{aligned}
$$

iii. Runner diameter: Diameter of runner is selected depending upon the flow conditions. If there is larger 
flow through the turbine select a large diameter of turbine and for the low water flow conditions select a smaller diameter of turbine.[9]

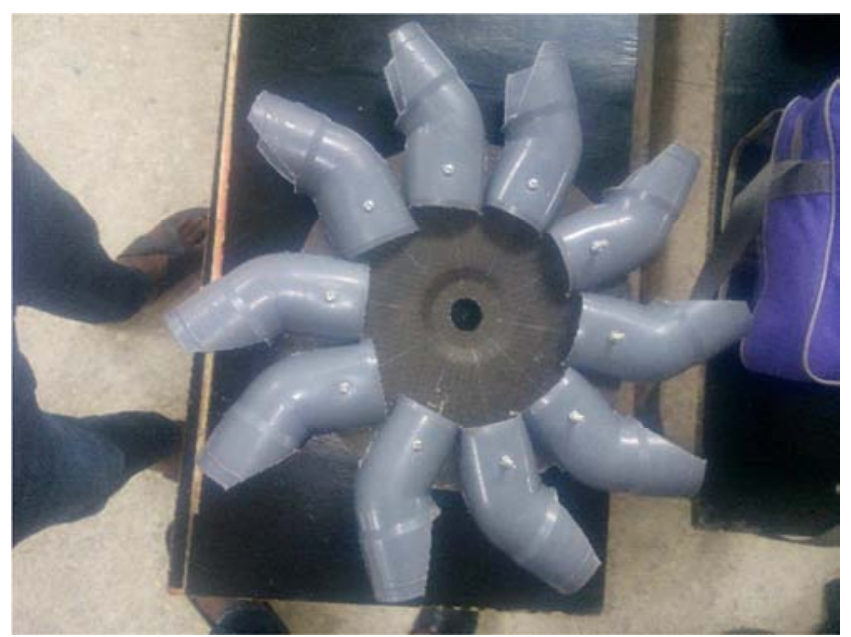

Figure 2 Pelton turbine wheel (BACK).

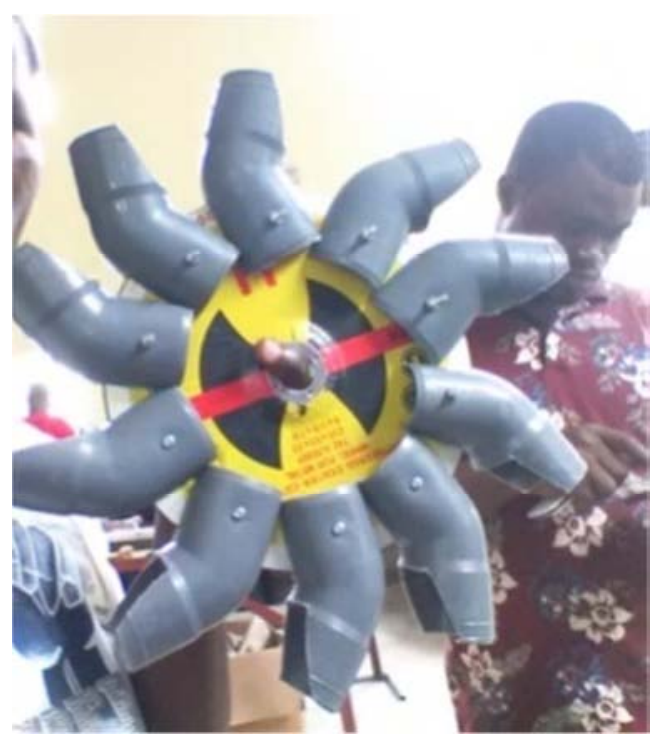

Figure 3. Pelton turbine wheel (FRONT).

\subsection{Turbine Power}

Hydro-electric generation depends on falling water. Water flow is the fuel of a hydro-turbine power plant and without it generation ceases. Regardless of the water path (either an open channel or penstock), the power generated in a turbine compartment is given as:

$$
P=H * Q * g * e
$$

(Wikipedia, Compendium in Small Hydro, 2000/2002) where,

$\mathrm{P}=$ Power (in Kilowatts) generated in the turbine shaft.

$\mathrm{H}=$ Net Head

$\mathrm{Q}=$ Water Flow Rate $\left(\mathrm{m}^{3} \mathrm{~s}^{-1}\right)$.

$\mathrm{g}=$ Force of Gravity $\left(9.81 \mathrm{~ms}^{-2}\right)$

$\mathrm{e}=$ Overall Turbine Set-Up Efficiency (normally 60 80\%) (Compendium in Small Hydro, 2000/2002)

\subsection{A. C. Generator/Alternator}

It is made up of a rotor and a stator and electricity is produced in it via the principle of electro-magnetic induction; which states that when a conductor is moved across a magnetic field so as to cut through the lines of flux created by a magnetic material, an electromotive force (e.m.f.) is produced in the conductor.

On the stator, the number of poles ( $\mathrm{N}$ and $\mathrm{S}$ ) is dependent on the number of magnets installed, and this is always in the multiple of 2 (that is, $2,4,6 \ldots$ ).

The relationship between the number of magnetic poles and number of coil windings is determined basically by the number of phase the generator is to have (that is single-phase or multiple-phase generator).

For a single-phase generator, the number of coil windings should be equal to the number of magnet poles (that is if we have a 10 poles rotor, the stator should consist of 10 coil windings);

The total number of turns the coil windings should have is dependent on the expected output voltage, the frequency of generation, rotor speed, magnetizing strength of the magnets and the cross-sectional area of the magnets. This is given mathematically as:

$$
N=\frac{E}{B * A_{T} * W * \sin W_{t}}
$$

where,

$\mathrm{N}=$ Total number of coil turns

$\mathrm{E}=$ Generated output voltage (in Volts)

$\mathrm{B}=$ Magnetic flux density (in Tesla) $\mathrm{m}^{2}$ )

$\mathrm{A}_{\mathrm{T}}=$ Total cross-sectional area of the magnets $=A^{*} \mathrm{M}$ (in

$\mathrm{W}=$ angular velocity $=2 * \pi * \mathrm{f}($ in radians/second $)$ where, $\mathrm{Pi}=3.41$

$\mathrm{F}=$ frequency of generation: usually between $50 \mathrm{~Hz}$

$\mathrm{t}=$ instantaneous time

At 90 degrees angular velocity and time, $\mathrm{t}=1$, sinwt becomes 1; therefore insignificant.

Determination of the frequency of generation is dependent on the rotational speed of the rotor and it is related by:

$$
N_{S}=\frac{2 F}{P}(r p s)
$$

where,

$\mathrm{N}_{\mathrm{s}}=$ Rotational speed of rotor as determined by a tachometer (in revolution/second)

$\mathrm{f}=$ frequency of generation (in Hertz)

$\mathrm{p}=$ number of poles

Therefore, the root mean square value of the generated voltage is given by

$$
V_{R M S}=0.707 * E(\text { volts })
$$

The power rating of the generator is majorly dependent on the current-carrying capacity of the conducting coils, as a current-consuming device with rating higher than that of the generator's conducting coil will burn off the coils if 
connected to the generator. This leads us to the power formula:

$$
P=V * I
$$

where,

$$
\begin{aligned}
& \mathrm{V}=\text { Voltage (in Volts) } \\
& \mathrm{I}=\text { Current (in Amperes) }
\end{aligned}
$$

Therefore, the generator will generate $200 \mathrm{~V}$ (peak voltage) and has a current-carrying capacity of 7A, its total output power will be 1,400 Watts (1.4 kW, neglecting all losses)

Adequate insulation is required for the conducting coils as they get hot while on load and light insulation wears off quickly with little temperature increase and this can lead to burning off of the coils or in some cases, damage of load, shock, etc. The alternator will be made of a permanent magnet rotor and a conducting coil stator.

\subsection{Stator Design}

The conducting coil windings (whose inner diameter is equal to the measurement of the magnet) will be connected in an alternating way: first coil winding, wound clock-wise is been connected to the second coil which will be connected anti-clockwise and this connection continues till the last coil winding is been connected.

Total number of turns per coil is 237

\section{Implementation}

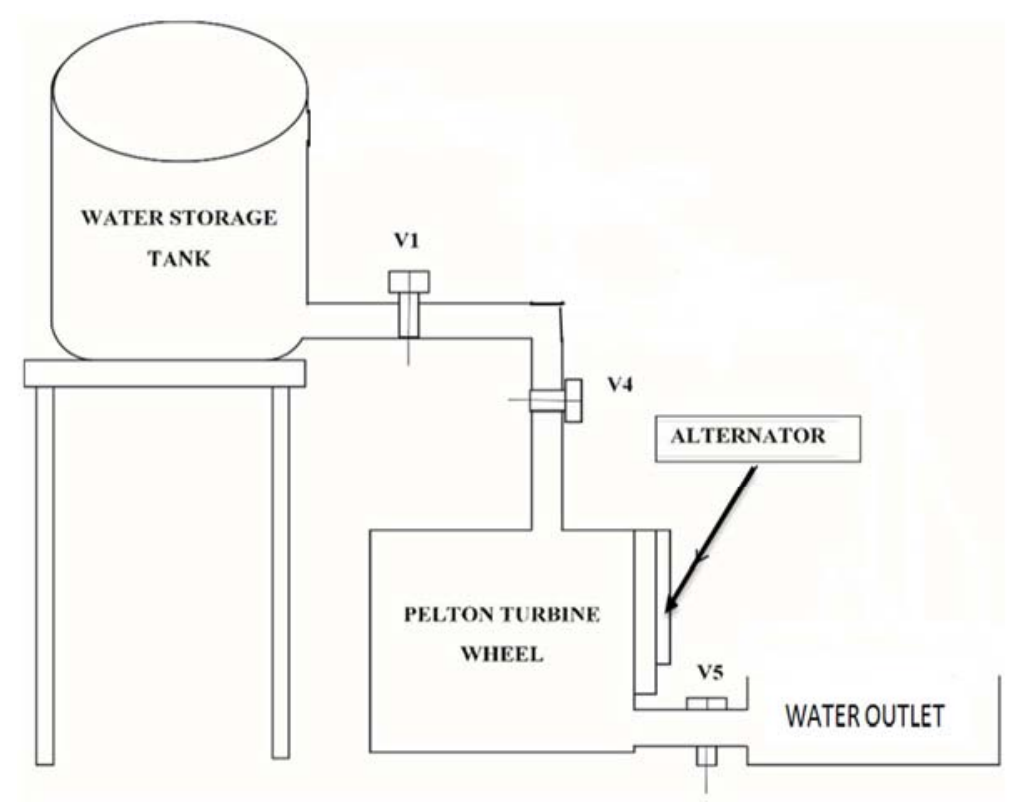

Figure 6. Hydro turbine setup.

The implementation/construction of this project will be discussed in three (3) major sections;

1. Alternator construction and rectifier circuit

2. Construction of pelton turbine wheel

3. Construction of Turbine casing

Alternator Construction

The construction procedure is sequentially outlined below:
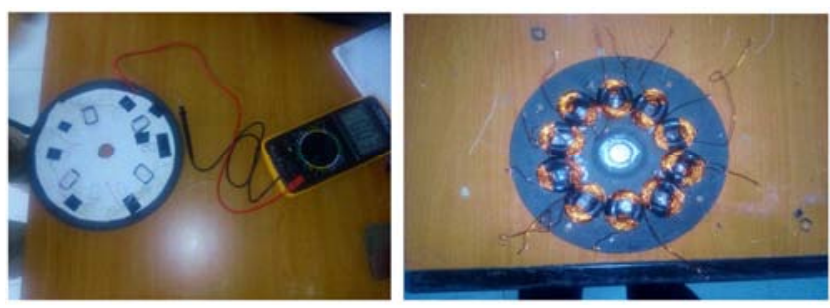

Figure 4. Stator coil (testing and construction).

\section{Rotor Design}

The magnets will be positioned evenly on the 9-inches $2 \mathrm{~mm}$ plastic glass with alternating poles $(\mathrm{N}, \mathrm{S}, \mathrm{N}, \mathrm{S}, \mathrm{N} \ldots)$.

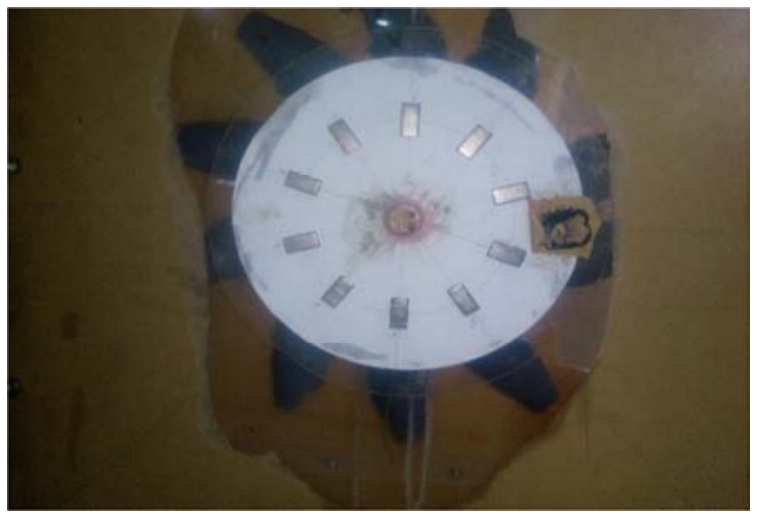

Figure 5. Rotor (N50 Neodymium magnet). i. Cut out a 9 inches, $2 \mathrm{~mm}$ plastic glass and place rotor template to fit into 10magnet.

ii. Then wound the coils around from left to right, pressing tight against the bobbin (which has the shape of the magnet) and counting the number of turns according to the design values;

iii. At complete coil wound, a lead was extended from the 
winding as the tap terminal before progressing. Using sand paper, we sanded off the insulation coating of the extended lead to reveal the copper before joining the conductor to the termination cable. The joints were soldered for improved reliability and then concealed with insulating material.
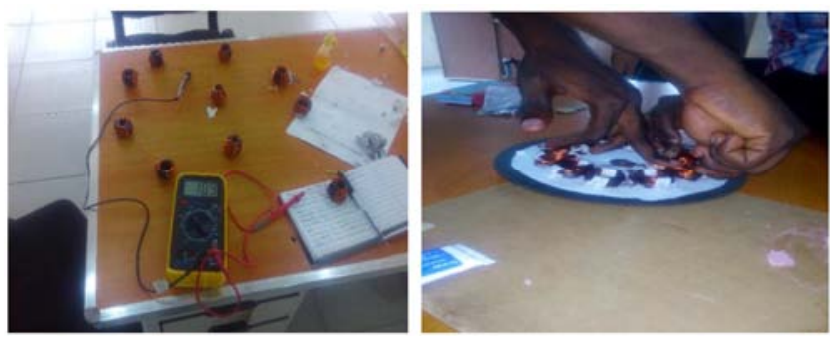

Figure 7. Winding the Alternator coils.

iv. When the winding was completed, the coils were assembled on the 9inch metal cutting disc and applied lamination core in the windings.

v. Finally, vanish was applied on the coil to reduce the air gap between the coils and also to bond each coil as one, test was carried out on the finished windings for continuity and resistance.

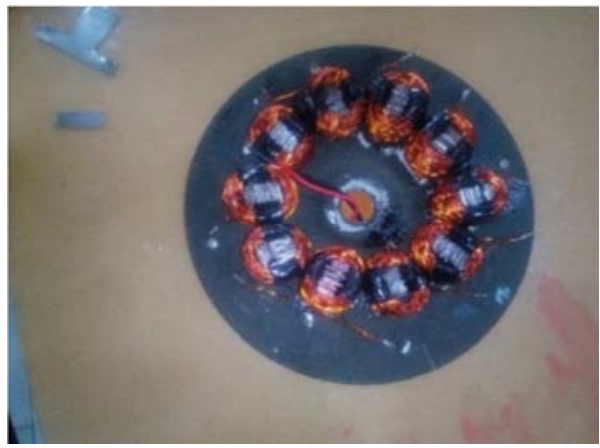

Figure 8. Completed Stator Winding.

The turbine casing was fabricated from $2 \mathrm{~mm}$ plastic glass. The turbine and the rotor were attached together through a shaft and bearing on a strong metal base and covered with a metallic body which met the requirements for strength, durability and heat dissipation.

The plastic glass was chosen to allow visual inspection of the unit without dismantling the casing.

\section{Fabrication of Pelton Turbine Wheel}

The Pelton-Wheel turbine was chosen because of its easy fabrication/construction at the domestic level, and it will be made of locally-sourced materials including metal-cutting disc, 45 degrees PVC elbow joints, bolts, nuts, washers (or bearings), etc.

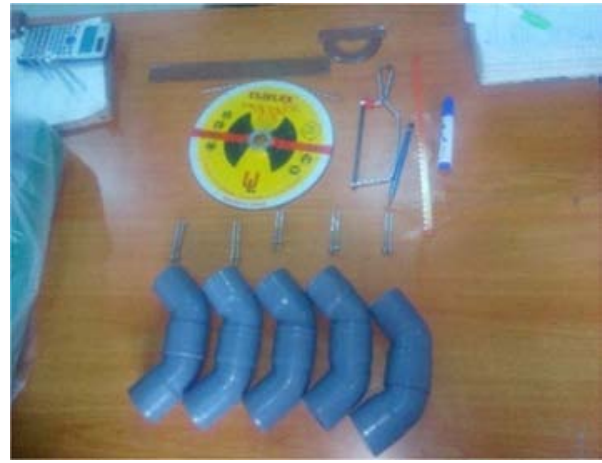

Figure 9. Turbine Wheel Material.

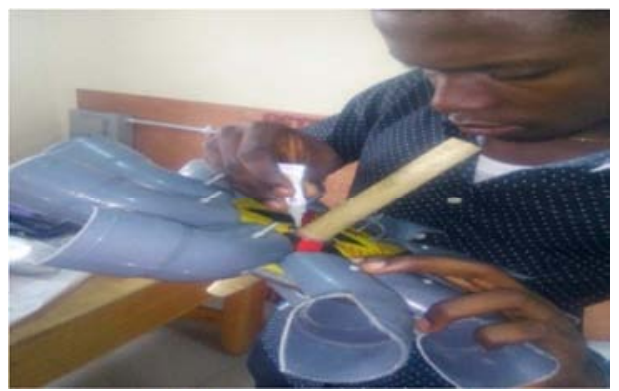

Figure 10. Fixing of shaft to the turbine wheel.

\section{Results}

Table 1. The voltage, current and speed are determined using three different flow rate.

\begin{tabular}{lllll}
\hline s/n & $\begin{array}{l}\text { FLOWRATE } \\
\text { (liter/sec) }\end{array}$ & Half flow 4 & $\mathbf{3}$ /4 flow 1 & $\begin{array}{l}\text { Full flow } \\
\mathbf{2 . 5}\end{array}$ \\
\hline 1 & VOLTAGE(V) & 0.462 & 0.869 & 1.18 \\
2 & CURRENT (mA) & 45 & 80 & 100 \\
3 & SPEED (rpm) & 115 & 383.5 & 520 \\
\hline
\end{tabular}

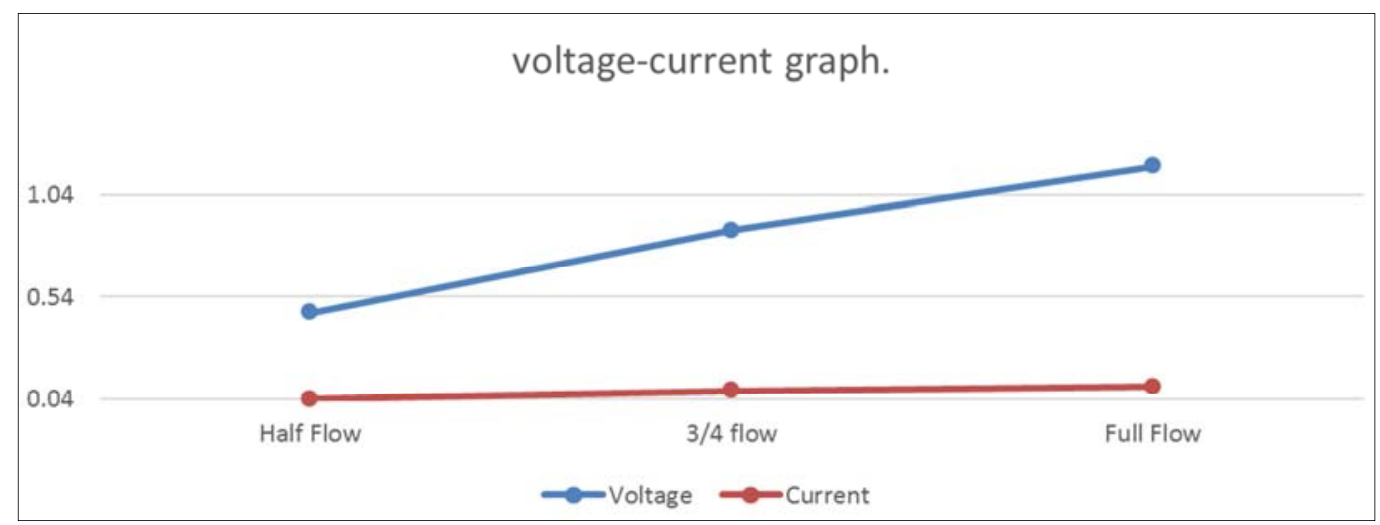

Figure 11. The graph below shows the relationship between the output current and voltage at different flow rate. 


\section{Discussion}

Oscillator Output

Below is the oscillator output of the turbine at $50 \mathrm{~Hz}$ frequency.

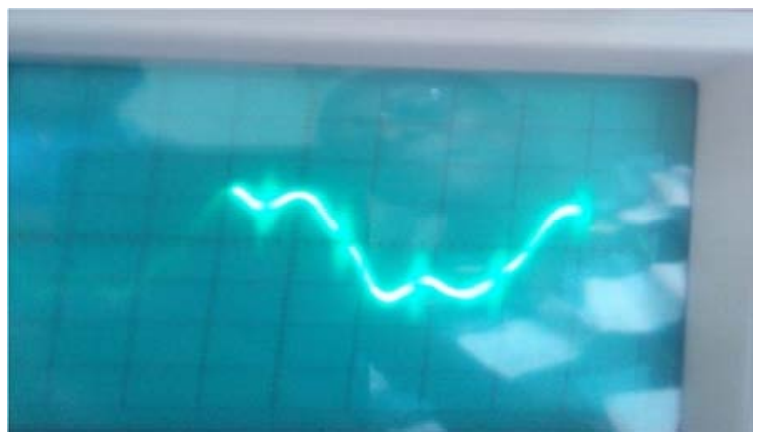

Figure 12. Oscillator output.

\section{Conclusion}

The objective of this research was achieved. A new cost effective mini hydro turbine power plant for Emerging society which was able to generate electricity for basic use was built. With the unique design of this hydropower turbine, it is able to generate electricity at different flow rate; the most effective generation was at full opening of the valve.

The merit of this design is the flexible rotation of the blade as water fall on it and the generation of electricity at different flow rate, thus increasing the efficiency of the machine.

This design has many advantages over other methods of hydroelectric power production. For example, it has very low noise when in operation compared with conventional waterwheel. Moreover, this design is environmentally friendly. This design is also cost effective while it uses less expensive and durable materials also the design does not significantly interrupt the water flow.

\section{References}

[1] Raabe IJ (1985). Hydropower: The design, use and function of hydro-mechanical, hydraulic and electrical equipment. Duesseldorf: VDI-Verlag.

[2] Biswas AK. In: El-Hinnawi B, Biswas AK (1981). Hydroelectric energy. Renewable sources of energy and the environment. Dublin: Tycooly International Publishing.

[3] Moreira JR, Poole AD. In: Johansson TB, Kelly H, Reddy AKN, Williams RH (1993).

[4] Havery A (1993). Micro-hydro design manual. A guide to small-scale water power schemes. London: Intermediate Technology Publications.

[5] B. L. Theraja, A. K. Theraja (2002). A Textbook of Electrical Technology Chapter 39 Alternators pages 1301-1383. Twenty - third Edition

[6] John Bird (2001), Electrical Circuit Theory and Technology Chapter 14 Alternating Voltages and Current Pages 193-204. Second Edition.

[7] Https://en.m.wikipedia.org/wiki/Hydro_Power_Plant.

[8] Bilal Abdullah Nasir (2013) Design of High Efficiency Pelton Turbine for Micro-Hydro Power Plant. International Journal of Electrical Engineering and Technology, Hawijah Technical Institute, Kirkuk, Iraq.

[9] Bilal Abdullah Nasir (2014) Design Considerations of Micro Hydro-Electric Power Plant. The International Conference on Technologies and Materials for Renewable Energy, Environment and Sustainability, TMREES14, Hawijah Technical Institute, Kirkuk, Iraq. 